\title{
Cidade-empresa e megaeventos, uma construção discursiva sobre as cidades
}

\section{City-company and mega events, a discursive construction on cities}

\author{
Vania Oliveira Fortuna \\ Universidade Federal Fluminense
}

Doutoranda em Comunicação (UFF) e Mestre em Comunicação (UERJ). Atualmente é professora dos cursos de jornalismo e publicidade da Universidade Veiga de Almeida e do IBMEC- RJ

\section{Resumo}

A cidade do Rio de Janeiro está sendo redimensionada por diferentes instâncias discursivas que desejam formar um consenso público sobre as transformaçôes urbanas necessárias para que a cidade ocupe um lugar de destaque no mercado internacional das cidades. Os megaeventos são fundamentais neste processo, uma vez que são estratégias importantes à competitividade urbana. Por conta desta competição, as cidades passaram a agir como empresas e a tratar o urbano como um negócio, que se concretiza material e simbolicamente no plano estratégico da cidade. Discutir a cidade-empresa e os megaeventos como estratégias discursivas do planejamento estratégico é a nossa proposta neste trabalho.

Palavra-chave: Cidade-empresa, megaeventos, plano estratégico

\begin{abstract}
The city of Rio de Janeiro is being resized by different discursive bodies who wish to form a public consensus on urban transformations necessary for the city to occupy a prominent place in the international market towns. Mega-events are critical in this process, since they are important for urban competitiveness strategies. Because of this competition, the cities began to act like businesses and treat the city like a business, which materially and symbolically embodies the city's strategic plan. Discuss company-city and mega events such discursive strategies of strategic planning is our proposal in this paper.
\end{abstract}

Keywords: city-company, mega-events, strategic plan 
A cidade é a tentativa mais bem-sucedida do homem de refazer o mundo em que vive mais de acordo com os desejos do seu coração. Mas, se a cidade é o mundo que o homem criou, é também o mundo onde ele está condenado a viver daqui por diante. Assim, indiretamente, e sem ter nenhuma noção clara da natureza da sua tarefa, ao fazer a cidade o homem refez a si mesmo (PARK apud HARVEY, 2013, p. 9).

Queremos hospitais e escolas no padrão FIFA. Era um país muito engraçado, não tinha escola, só tinha estádio. Estas são frases de dois cartazes que no meio de tantos outros deram o tom das manifestaçóes que ocuparam as ruas das cidades brasileiras em de junho de 2013, não por acaso a uma semana do início da Copa das Confederações. O padrão FIFA é evocado pela população porque ele é percebido internacionalmente como um selo de qualidade, uma garantia de sucesso face às exigências feitas por essa instituição às cidades-sede de megaeventos esportivos. Os primeiros protestos foram contra o aumento de R \$ 0,20 nas tarifas dos transportes públicos, liderados pelo Movimento Passe Livre, em São Paulo, que acabou se espalhando por todo o país. O pleito pela queda do aumento dessas tarifas foi apenas uma fagulha na explosão de insatisfações que rapidamente vieram à tona em uma série de mobilizaçôes que reivindicavam educação, saúde, habitação, transportes públicos de qualidade, reforma política e punição de políticos e empresários corruptos.

Os manifestantes também demonstraram indignação pela aplicação do dinheiro público em transformaçôes urbanas demandadas pelos megaeventos, assim como pela ausência da participação popular nesse processo. Para além da cobrança pela satisfação das necessidades básicas, percebemos uma reivindicação simbólica que se sobrepunha às questóes objetivas. As pessoas queriam (e querem) exercer o direito à cidade. Direito a participar da esfera pública que pensa o espaço urbano. Direito a usar a cidade, desvendar seus mistérios, testar suas possibilidades, sem pagar caro por isso. Mas, segundo David Harvey (1993), nada disso é possível, porque a qualidade da vida urbana virou uma mercadoria. Os discursos levam a crer que há liberdade de escolha de serviços, lazer e cultura, mas tudo isso pode ser desfrutado desde que se tenha dinheiro para pagar. Essa "pseudo" liberdade que sentimos mascara a ausência de práticas democráticas no uso da cidade.

O direito à cidade se torna bem mais do que o direito individual de ter acesso a serviços públicos de qualidade. Se nós somos a cidade e se a cidade somos nós, como Park sugere na epígrafe que abre esta introdução, podemos pensar que ter direito à cidade é ter mais liberdade de viver e experimentar os espaços que criamos e recriamos constantemente. Ignorar essa relação de sobrevivência mútua é aceitar uma cidade sem sentidos. Para Harvey (2013), esse direito é mais coletivo do que individual à medida que as remodelaçóes urbanas dependem de um poder coletivo. Negar à população o direito de participar do fazer e refazer a cidade é um dos mais importantes direitos humanos comumente negligenciados. O autor afirma 
que se Park está certo quando diz que ao refazermos a cidade estamos refazendo a nós mesmos, temos que avaliar constantemente não só as nossas atitudes como as dos outros. Quando percebemos que o nosso cotidiano está estressante e sem motivação, temos o direito de mudar de rumo, porque "a questão do tipo de cidade que desejamos é inseparável da questão do tipo de pessoas que desejamos nos tornar. A liberdade de fazer e refazer a nós mesmos e a nossas cidades dessa maneira é, sustento, um dos mais preciosos de todos os direitos humanos". (HARVEY, 2013, p. 9).

No Brasil, o Rio de Janeiro é o protagonista das discussões sobre transformaçóes urbanas e megaeventos, especialmente por ser sede dos Jogos Olímpicos de 2016. O Rio vem sendo discursivamente construído para ocupar uma privilegiada posição no concorrido mercado internacional das metrópoles, e a partir do "orgulho" coletivo dessa consagração, formar uma nova identidade carioca. Os governos federal, estadual e municipal se uniram em prol dos megaeventos, argumento que historicamente se tornou eficaz para atrair investimentos e mostrar ao mundo o quanto uma cidade pode ser maravilhosa. Mas maravilhosa para quem, se no rastro dessas táo famosas reestruturaçóes urbanas emergem processos de exclusão de camadas da sociedade, desapropriaçóes e protestos de diferentes segmentos da sociedade?

Com efeito, os megaeventos não são os grandes causadores da atual insatisfação urbana, até porque não precisaríamos de tantas obras e remoçóes para sediar a Copa do Mundo e os Jogos Olímpicos, mas a população já entendeu que eles servem como argumento para alguns mandos e desmandos sobre a cidade, deixando nítida a falta de democracia urbana. Achamos interessante relembrar as manifestaçôes que começaram em junho de 2013 porque elas expressam a crise de um modelo de cidade que vamos discutir neste trabalho. Quando a cidade pensava que poderia apenas ser surpreendida pelos resultados dos jogos da Copa das Confederaçóes, surgiu o improvável, o imprevisto, deixando claro para as diferentes instâncias que trabalham a imagem competitiva do Rio que os consensos são imaginários e que a cidade não pode ser domesticada, pois seus sentidos transcendem suas representaçôes.

Usar os megaeventos como estratégia discursiva para transformar material e simbolicamente as cidades não é algo novo. A história das cidades revela isso, notadamente com as Exposiçóes Universais de Londres (1851), Paris (1855) e no caso específico do Rio de Janeiro, 1922. Entretanto, esta dinâmica firma-se deliberadamente como uma das principais estratégias do modelo de cidade perseguido por aquelas que desejam competir no mercado internacional das cidades. Cidades que atuam como empresas, pois adaptam o planejamento estratégico empresarial à questão urbana. O Rio de Janeiro foi capturado pela lógica da cidade-empresa, e como tal utiliza-se do planejamento estratégico desde os anos 90 para adequar-se ao modelo de cidade difundido no Brasil e na América Latina por consultores catalães1, que usam, especialmente, o sucesso de Barcelona 
como paradigma de suas análises e propostas. Este percurso é fundamental para entendermos o "Rio dos megaeventos", uma cidade que vira uma arena de lutas simbólicas diante das transformaçóes urbanas para receber os Jogos Olímpicos de 2016. Esta é a proposta da nossa discussão.

\section{O embate entre polis e city}

DDa ocupação dos espaços públicos do Rio de Janeiro pela população insatisfeita com os rumos políticos que tomam a cidade, assim como pela oposição feita por Carlos Vainer entre polis, espaço em que se firmam "o encontro e confronto dos cidadáos", e city, "impondo-se à cidade como espaço e objeto e sujeito de negócios” (2012, p.101), veio a nossa inspiração para o nome deste subtítulo, já que aqui queremos discutir os discursos que fazem do urbano um grande negócio, que por vezes sufocam as subjetividades próprias da cidade. Perceber a cidade como polis nos permite seguir por caminhos sensíveis que expressam sua polifonia, suas diferentes formas de significação. $\mathrm{O}$ embate polis $x$ city também é denunciado por Guattari (1992), que defende a urgência da "restauração da cidade subjetiva”. O homem está desterritorializado especialmente pela circulação de informaçôes e simulaçóes propostas pela informática e pelos meios de comunicação. Quase não há mais surpresas, o que ameaça a subjetividade de paralisia. A cidade neste contexto é determinante porque ela é produtora de subjetividades individual e coletiva. A cidade é, por essência, subjetiva, pois "engaja tanto os níveis mais singulares da pessoa quanto os níveis mais coletivos. De fato, trata-se de todo o porvir do planeta e da biosfera", que tem o poder de resingularizar a atividade humana esvaziada por imposiçóes da modernidade a partir das "verdadeiras errâncias do desejo, às quais as desterritorializaçóes técnico-científicas, urbanas, estéticas, maquínicas de todas as formas nos incitam" (GUATTARI, 1992, p. 170).

Se para Guattari o porvir da humanidade é inseparável do devir urbano, a preocupação com o futuro das mentalidades urbanas é uma questão. Para o autor, não existe mais uma capital que domine uma economia mundial, e sim um "arquipélago de cidades" (grandes cidades) conectadas pela telemática e pelos meios de comunicação que sobressaem internacionalmente, ao passo que nas cidades pobres acumulam-se as favelas e as diferenças sociais. Somente a transformação das mentalidades e uma reorientação para o meio ambiente poderão equilibrar o planeta. Na verdade, é toda uma competição entre empresa e naçóes que deve ser repensada para que as problemáticas urbanas sejam efetivamente reconhecidas como meio de produção de subjetividades. Para que os objetivos sejam alcançados, a aliança com múltiplos parceiros é possível desde que as negociaçóes não sejam baseadas numa relação de dominação. Trata-se de uma cultura política que precisa ser reconstruída com a participação do usuário da cidade, uma nova experiência urbana cujos operadores são o arquiteto e o urbanista, que devem produzir subjetividades pela articulação das singularidades, como a preocupação em construir espaços que contemplem as necessidades da criança, do 
idoso, do deficiente físico. Mas isso não é tarefa fácil, visto que Guattari ressalta que tais profissionais, artistas criadores da subjetividade coletiva, encontram-se pressionados por múltiplas coaçôes materiais e sociais.

O Rio de Janeiro quer fazer parte do "arquipélago de cidades" citado por Guattari e, infelizmente, está longe de restaurar-se como uma "cidade subjetiva", visto que não se identifica uma mudança de mentalidade. As parcerias público-privadas imprimem a dominação dos objetivos empresariais, da especulação imobiliária e do atendimento às classes abastadas em detrimento das singularidades da cidade. Usa-se a necessidade de preparar a cidade para os megaeventos como produção de subjetividades que tem a superficialidade como companheira. Isto compromete a reinvenção do seu devir urbano e pode condená-la a "aparecer sob o peso de seu próprio imobilismo, que ameaça atualmente torná-la impotente face aos extraordinários desafios com os quais a história a confronta" (GUATTARI, 1992, p. 178). Para nós, é a city impedindo a produção de subjetividades da polis.

Assim como Guattari (1992), Park e Harvey (2009) e Sennett (2006) reconhecem a cidade como locus de poder, cujos espaços foram construídos à imagem do próprio homem. Mas diante do estranhamento e da falta de aceitação das diferenças, essas imagens se estilhaçaram, sustentando a resistência à dominação. No Rio de Janeiro, em 2013, assistimos a tentativa dessa resistência. As "vozes das ruas" estavam "fora do discurso", resistindo, desorganizando esse espaço próprio de significação que é a cidade. Eni Orlandi (2004) chama essas situaçôes discursivas de falas desorganizadas que:

significam lugares onde sentidos faltam, incidência de novos processos de significação que perturbam ao mesmo tempo a ordem do discurso e a organização do social. O conhecimento desses processos contribui para a melhor compreensão do que tem sido tratado sob o nome genérico de "conflito social". (ORLANDI, 2004, p. 63)

Tentando compreender a cidade pelo discurso, Orlandi (2004) propóe uma reflexão sobre a relação de significação entre as dimensôes culturais, históricas, econômicas e sociais. Esta perspectiva permite ir além do olhar organizado e organizador do urbano, que quando menos se espera é desestabilizado por acontecimentos que produzem novos sentidos. É a materialidade da cidade desorganizando esse lugar totalizador, pois corpos e cidade formam um corpo único significativo que está em constante movimento, que se faz e desfaz a cada dia que amanhece e que promete que nada será como antes "num espaço material concreto funcionando como sítio de significação que requer gestos de interpretação particulares. Um espaço simbólico trabalhado na/pela história, um espaço de sujeitos e de significantes" (ORLANDI, 2004, p. 32).

O "Rio dos megaeventos" vive um momento complexo por conta da nova ordem imposta pela cultura das gestôes urbanas, que deseja que a cidade concorra no competitivo mercado das metrópoles. Mas essa dinâmica também foi 
percebida em épocas passadas. Basta ler alguns jornais do começo do século XX, como a Gazeta de Notícias e o Correio da Manhã. A construção da Avenida Central, o desmanche do Morro do Castelo, a construção de pavilhóes para a Exposição Universal de 1922, a retirada dos cortiços da área central, o aterramento do que é hoje o Flamengo comprovam que na busca de visibilidade, de se mostrar uma cidade com eficiente infraestrutura, a reconfiguração urbana sempre foi a ferramenta adotada para a cidade consagrar-se civilizada, moderna. Apesar de a cidade ser institucionalmente organizada, simbolicamente organização e desorganização caminham juntas. A desorganização irrompe a lógica de açôes públicas que utiliza o planejamento urbano como instrumento discursivo para a legitimação do "pensamento único",1 consenso construído em torno da imagem de cidades que, inspiradas em referências de modelos bem-sucedidos, propóem projetos urbanos com grande visibilidade midiática que inclui, sobretudo, a revitalização de áreas centrais degradadas, construção de prédios e museus espetaculares, parcerias público-privadas e melhoria significativa na qualidade de vida dos moradores locais. Sáo passos em busca do resgate da autoestima e da consagração da cidade como empreendedora e global.

Este é o caso do Rio de Janeiro, que através da Operação Urbana Porto Maravilha quer ser percebido como uma nova cidade a partir do "renascimento" de sua área portuária. Os megaeventos têm uma participação fundamental neste contexto, posto que a necessidade de preparar a cidade para recebê-los, principalmente os Jogos Olímpicos de 2016, foi o grande argumento para que um projeto antigo, já delineado na gestão do então prefeito Cesar Maia (1993-1996/ 20012004 /2005-2008), tornar-se realidade na gestão do prefeito Eduardo Paes (2009 - 2012 / 2013-2016). Rircardo Ferreira Freitas (2011) propóe uma conceituação para megaeventos inspirado no conceito de fato social de Durkheim, um fato determinante nas alteraçóes do cotidiano de uma coletividade, caracterizando-se por três vertentes: a coercitividade relacionada a fortes padrôes culturais do grupo que os indivíduos integram; a exterioridade desses padróes de cultura; e a generalidade, ou seja, os fatos sociais existem para a coletividade. Nesse sentido, Freitas considera que os impulsos coercitivos de um megaevento acabam sendo suas próprias reverberaçóes que acontecem em geral na mídia, e a chave para o entendimento dessa ligação é o poder coercitivo de um megaevento, pois todo o envolvimento da sociedade em torno desse acontecimento, como as modificaçóes que ocorrem na rotina da cidade com relação ao trânsito; o funcionamento dos transportes públicos; do comércio; a alteração na interação dos indivíduos entre si, bem como um olhar mais carinhoso e feliz da cidade, são aspectos que o autor chama de reverberaçóes causadas pelo megaevento. Os meios de comunicação, portanto, "potencializam a magnitude de um megaevento. Ao mesmo tempo em que se retroalimentam das reverberaçóes, eles causam o envolvimento coletivo para continuar noticiando e anunciando. Daí considerarmos o megaevento como um fenômeno social midiático" (FREITAS, 2011, p. 9).

Cidade e empresa. Os papéis se misturaram e uma nova concepção de 
cidade entrou em cena. Competição. Esta é a palavra de ordem que impulsiona as cidades que buscam a aprovação das forças do mercado mundial. São cidades (re)configuradas por um protagonismo de gestão que atende à lógica financeira e trata o urbano como um negócio. E se a cidade é percebida como uma oportunidade de negócio, nada mais natural do que os governos se renderem àqueles que entendem de negócio: os empresários. A parceria público-privada torna-se fundamental nesse processo de empreendedorismo urbano, que se caracteriza pela recuperação de antigas centralidades, criação de novas centralidades e atração de investidores e cidadãos-consumidores, sendo que o grande desafio dos centros urbanos na atualidade é diagnosticar o que prejudica o seu desenvolvimento, bem como definir políticas públicas que sustentem um projeto de cidade digno de inserção na economia mundial. Vainer (2012) afirma que o desejo de vender a imagem do Rio no mercado simbólico leva a cidade a operar como uma empresa, em que a mídia mascara as contradiçóes e trava um debate silencioso para aproveitar as oportunidades de negócios geradas pelos megaeventos.

Compartilhamos com Vainer a ideia de que o Rio opera como uma empresa, e percebemos que este projeto de cidade começa a ser delineado em 1992, inspirado pelo modelo Barcelona. As grandes cidades cada vez mais atuam como empresas, e o Rio desempenha esse papel à medida que seu desenvolvimento depende de fatores econômicos; prepara-se para a concorrência internacional e gerencia atividades produtivas, serviços e recursos humanos, atributos constitutivos do planejamento estratégico empresarial. Nesse sentido, "o planejamento estratégico, segundo seus defensores, deve ser adotado pelos governos locais em razão de estarem as cidades submetidas às mesmas condiçóes e desafios que as empresas" (VAINER, 2012, p. 76). Se a problemática da questão urbana tratava de temas como crescimento desordenado, trabalho, equipamentos de consumo coletivo, movimentos sociais urbanos e racionalização do solo, o autor ressalta que o "nexo central" das discussóes atuais é a competitividade urbana. E parte fundamental deste processo de competição é pensar a cidade como projeto.

\section{A cidade como projeto}

O Rio de Janeiro quer ser uma cidade global e para isso precisa ser uma cidade empresarial. Produtividade e competitividade se imprimem como açóes indispensáveis ao modelo de cidade difundido no Brasil e na América Latina por consultores cataláes, que usam, especialmente, o sucesso de Barcelona como paradigma de suas análises e propostas. $\mathrm{O}$ planejamento estratégico é um modelo de planejamento urbano que começou a ser pensado nos anos 60 a partir dos conceitos e técnicas do planejamento empresarial aplicado na Harvard Business School. Já que as cidades estavam submetidas aos mesmos desafios das empresas, por que não tentar utilizar estratégias empresariais para solucioná-los? Foi o que aconteceu e pareceu dar certo. $\mathrm{O}$ setor público apropriou-se das metodologias da gestão empresarial nos anos 80, nos Estados Unidos, quando diversas cidades americanas passaram a utilizar o planejamento estratégico como enfoque no 
desenvolvimento econômico.

O discurso para a construção de um projeto de cidade estrutura-se "na articulação de três analogias constitutivas: a cidade é uma mercadoria, a cidade é uma empresa, a cidade é uma pátria" (VAINER, 2012, p.77, grifos do autor). Isto nos remete de imediato pensar o Rio de Janeiro como uma mercadoria de luxo a ser consumida, promovida por uma gestão urbana que tem a exacerbaçáo do sentimento patriótico como um ponto forte da construção do consenso sobre a cidade. Os megaeventos neste contexto tornam-se estratégias ideais à medida que tais efervescências sociais reforçam sentimentos de pertencimento e orgulho nacional, além de atrair investimentos e consumo da e na cidade.

A cidade-mercadoria, a cidade-objeto de luxo, segundo Vainer, é uma das ideias mais populares dos neoplanejadores e nesta dinâmica o marketing urbano torna-se fundamental ao processo de planejamento e gestão das cidades. Mas o autor ressalta que a cidade é a mais complexa das mercadorias existentes, pois sua venda depende de quem se tem em vista como comprador. Idosos, religiosos e jovens são exemplos oferecidos por Vainer como compradores que possivelmente têm gostos diferenciados. Acrescentamos a estes exemplos as empresas que fazem parcerias com o governo local, porque ao mesmo tempo em que são co-produtoras das transformaçóes urbanas, consomem a cidade na forma dos privilégios e lucratividade oriundos dessas parcerias. O planejamento de marketing urbano depende do diagnóstico das características de cada cidade, visto que ela pode ser vendida a uma infinidade de mercados. Entretanto, Vainer chama atenção para o fato de que os autores que enaltecem um modelo de cidade competitiva desprezam as especificidades locais e valorizam o interesse do capital transnacional, como "espaços para convençôes e feiras, parques industriais e tecnológicos, oficinas de informação e assessoramento a investidores e empresários, torres de comunicação e comércio, segurança..." (VAINER, 2012, p. 79). Com efeito, preparar a cidade para receber megaeventos ou eventos corporativos é parte importante na construção de um projeto de cidade em que todos vendem a mesma coisa aos mesmos compradores, que têm as mesmas necessidades.

Estabelece-se um receituário neoliberal que para além do mercado externo visa um mercado constituído pela demanda de localizaçóes do capital, interesses que qualificam a cidade como mercadoria. Otília Arantes (2012) concorda com Vainer quando afirma que "a forma cidade é determinada pelas diferentes configuraçóes deste conflito básico e insolúvel”, pois "o valor de uso que o lugar representa para os seus habitantes e o valor de troca com que ele se apresenta para aqueles interessados em extrair dele um benefício econômico qualquer, sobretudo na forma de uma renda exclusiva" (2012, p. 26), uma história americana que fez da cidade uma máquina, que para produzir riquezas precisa de coalisóes de elite que conformam especulação imobiliária e seus derivados.

Vainer afirma que os pragmáticos consultores deixam claro que a abertura das cidades para o exterior é seletiva, visto que não se desejam visitantes 
e usuários em geral, muito menos imigrantes pobres expulsos de outros países igualmente pobres, querem visitantes e usuários solventes. $\mathrm{O}$ direito à cidade passa a ser diretamente proporcional ao índice de solvência de estrangeiros e visitantes, uma realidade que se transforma efetivamente em projeto, em estratégia de promoção da cidade. Mas para Vainer não bastava trabalhar os recursos infraestruturais e simbólicos constituintes dos valores de uso que o capital transnacional reconhecia na mercadoria cidade, era preciso seguir o modelo Barcelona, cujo plano estratégico operou um grande city marketing com foco na revitalização de áreas degradadas, construção de hotéis, promoçôes turísticas, segurança, eventos corporativos e projetos culturais.

No contexto de análise dessa nova concepção de cidade, a cidade é objeto e sujeito1, pois a cidade-coisa, a cidade-mercadoria pode também deixar a forma passiva de objeto para assumir a forma ativa de sujeito, uma empresa.

Conceber a cidade como empresa implica, segundo Vainer, uma "lógica implacável": o marketing lead city planning, exige que as decisóes sobre a cidade estejam nas mãos dos que decidem nas empresas. Nesse novo conceito de planejamento os interesses do mercado estão representados nas parcerias público-privadas, cujas formas de atuação vão da captação de recursos e execução de grandes intervençóes urbanas à gestão de equipamentos e prestação de serviços coletivos. As parcerias são na opinião de Borja \& Castells (1997) um dos principais mecanismos que conferem às cidades condições de inserção na competitividade urbana, consolidando um projeto de cidade definido por seu plano estratégico. Este projeto de cidade deve contemplar as novas funçóes dos governos locais enquanto promotores, cujos objetivos são promover a cidade para o exterior; favorecer a cooperação público-privada; desenvolver o "patriotismo cívico" e uma inovação político-administrativa. Nesse sentido, os autores propóem que a organização política local não faça uma administração centralizada nem uma "separação rígi$d a$ entre o setor público e privado” (BORJA \& CASTELLS, 1997, p. 159), pois uma gestão eficaz deve assegurar agilidade e transparência para atingir suas metas. Entretanto, Vainer critica essa proposta e diz que "o fim da separação rígida quer dizer, em bom catalão, participação direta, sem mediaçôes, dos capitalistas e empresários nos processos de decisão referentes ao planejamento e execução de políticas..."(VAINER, 2012, p.88, grifos originais do autor).

O Rio de Janeiro viveu e vive sob a experiência das parcerias público-privadas, com ênfase atualmente no Porto Maravilha. Vainer ressalta que em parceria com a prefeitura, um consórcio empresarial e associaçóes patronais conduziram de forma autoritária a cidade, negando a participação de segmentos tidos como irrelevantes do ponto de vista estratégico. A cidade-empresa supôe e propóe uma despolitização da cidade à medida que o plano político tornou-se um plano de gestão. Vainer considera central não pensar a cidade-empresa como uma proposta simplesmente administrativa, gerencial ou operacional, mas sim entender que o conceito de cidade e de poder público estão sendo ressignificados por uma operação que transforma a cidade em sujeito/ ator econômico que 
precisa ser competitivo, realista e não pode se dar ao luxo de produzir planos utópicos. $\mathrm{O}$ controle político dissolve-se em um espaço de competitividade urbana onde o que conta são os resultados.

Desenvolver o patriotismo cívico é um dos pilares que sustentam o projeto de cidade segundo Borja \& Castells (1996). A analogia cidade-pátria faz Vainer refletir sobre a necessidade do consenso. Diante de tamanha despolitização do espaço público, de negação da cidade enquanto polis, torna-se imprescindível ao planejamento estratégico o consenso sobre a cidade. A busca pelo consenso, segundo o autor, está pressuposta no discurso que trata a "cidade como unidade: a cidade compete, a cidade deseja, a cidade necessita. Enquanto se discute se as cidades competem ou não, e o que elas desejam, aceita-se, como natural, a instauração da cidade como sujeito - sujeito simples, coeso, sem qualificação". (VAINER, 2012, p. 91). O patriotismo da cidade e a consciência de crise ocupam lugar de destaque no projeto ideológico dos cataláes.

$\mathrm{Na}$ referência que fazem a Barcelona e a outras cidades que obtiveram sucesso, a consciência de crise está presente como ponto de partida para a imposição das transformações. Se diferentes instâncias públicas e privadas apontam, repetidamente, problemas com áreas degradadas e improdutivas, violência, mobilidade urbana comprometida por falta de vias de acesso e transporte público deficiente, como é o caso do Rio de Janeiro, naturaliza-se a ideia de que a cidade precisa mudar, especialmente para atender às necessidades internas. Sob a naturalização da necessidade de mudança aplica-se um projeto de cidade bem-sucedido em que se espera o mínimo de questionamentos sobre ele.

Já que o sentimento de crise é passageiro, o consenso deve ser construído em base mais sólida. É preciso que o sentimento de crise transforme-se em um consistente patriotismo de cidade. Para Vainer, um dos principais elementos do planejamento estratégico é "a criação das condiçôes de sua instauração enquanto discurso e projeto de cidade". O patriotismo da cidade é simultaneamente condição e resultado do projeto de cidade, pois "a unidade que se propunha no discurso unitário sobre a cidade é a unidade que se pretende construir" (VAINER, 2012, p. 94). Nesse sentido, monumentos, esculturas, a beleza estética de praças e jardins e boa infraestrutura urbana dão dignidade cidadã e reforçam identidades. Para o nosso trabalho, fica claro que a criação de consciência de crise e o patriotismo da cidade são elementos fundamentais à construção de um consenso sobre a necessidade das parcerias público-privadas.

Se todo esse processo impóe-se claramente como antidemocrático, ou como Vainer afirma uma "democracia direta da burguesia”, para Borja \& Castells (1996) trata-se de uma inovação democrática. Esta inovação é o mais excitante aspecto desse papel promotor que gradativamente os governos locais assumiram. A participação dos cidadáos, a cooperação social e a integração das políticas urbanas são os propósitos dessa inovação. O ideal é que se tenha maior democracia local, permitindo o engajamento dos cidadáos nas decisóes municipais. Uma 
crise de identidades coletivas e de participação nas instituiçóes e nos partidos políticos, além da constatação de que o governo sozinho não tem capacidade para atender às demandas sociais são suficientes para uma proposta inovadora de democracia que estreite a relação entre administradores e administrados, visando dividir responsabilidades e soluçôes nos problemas coletivos por meio de uma cooperação social. Com efeito, o âmbito local tornou-se o locus para as experiências de novas fórmulas eleitorais, descentralização territorial e participação na gestão pública. Essas questôes são legitimadas pelo princípio de proximidade, que para Borja \& Castells (1996) é um elemento indispensável à renovação democrática.

Em meio a essas negociações, Borja \& Castells (1997) reforçam a importância dos meios de comunicação no processo político, já que são neles que as eleiçôes se decidem. A competição entre as cidades fez emergir a figura do líder carismático. Os prefeitos precisam da mídia para a construção de uma personalidade confiável que desperte na população o apoio necessário às açóes empreendidas. Esta certamente é condição estruturadora do próprio projeto. Mais uma vez a experiência de Barcelona é exaltada porque a forte liderança do prefeito Maragall foi fundamental no processo de transformação da cidade. Borja \& Castells (1996) afirmam que dificilmente cidades que não são grandes capitais conseguiriam superar os desafios do planejamento estratégico sem a forte personalidade e dinamismo dos seus prefeitos. Ao mesmo tempo, Vainer chama atenção de que "aí encontraríamos as bases para entender o comportamento de muitos prefeitos, que mais parecem vendedores ambulantes que dirigentes políticos" (2012, p. 78). As propostas de Borja \& Castells (1996) nos é fundamental à medida que verificamos no projeto de cidade definido pelo plano estratégico do Rio de Janeiro, em 1992, comandado pelo então prefeito Cesar Maia, percebido como uma liderança carismática, a busca pelo atendimento a essas proposiçóes, o que vem se consolidado nos planos que o sucederam. Chamamos atenção para o atual prefeito Eduardo Paes, considerado uma figura carismática que utiliza sobremaneira o marketing urbano para "vender" o Rio como uma cidade ideal para investimentos e turismo, ingredientes indispensáveis à concepção de cidade-empresa, e evidentemente às proposiçôes consagradas por Borja \& Castells nos anos 90 .

Ermínia Maricato (2012) chama atenção para o fato de que historicamente o urbanismo brasileiro compromete-se apenas com parte da cidade. São “ideias fora do lugar" porque, a priori, o planejamento deve atender às necessidades do todo, mas também pode-se dizer que as ideias estão no lugar justamente porque, como sempre, seguem regras que privilegiam uma parcela da sociedade. Para a "cidade ilegal" (favelas ou quaisquer outras áreas cujo crescimento urbano se deu fora da lei) não há planos, pois "trata-se de um lugar fora das ideias" (MARICATO, 2012, p. 122). As periferias extensas com casas, transportes, luz e água precários são classificadas por Maricato como "não-cidades", lugares que mais uma vez ficaram fora das ideias dos neoplanejadores. Nesse sentido, a autora rejeita as noções de cidades como "atores políticos", defendidas por Borja \& 
Castells (1996), já que as cidades são lugares e não agentes ou atores que tomam a cidade como uma mercadoria, empresa ou pátria, conforme propóe Vainer. Os planos estratégicos vestiram uma roupagem democrática para serem vendidos às municipalidades latino-americanas, mas para Maricato servem ao ideário neoliberal também se afirmava democrático.

A ideia de fabricação de consenso a qualquer preço tornou-se a peça-chave da concorrência entre as cidades, uma fábrica de ideologias, segundo Arantes (2012), que usa sentimentos como o de comunidade e civismo para uma mobilização competitiva permanente. No centro das coalisóes que permitem tal dinâmica estão incorporadores, corretores, banqueiros, seguidos de coadjuvantes "como a mídia, os políticos, universidades, empresas esportivas, câmaras de comércio e, enfim, nossos dois personagens desse enredo de estratégias: os planejadores urbanos e os promotores culturais" (ARANTES, 2012, p. 27). São atores que na busca do consenso têm seus interesses representados no plano estratégico, para Maricato um plano-discurso que cumpre um papel ideológico, destacando "alguns aspectos para ocultar outros" (2012, p.148). E é sobre este plano-discurso que pensamos o conceito de cidade-empresa e sua busca pelo consenso, utilizando os megaeventos como importante estratégia discursiva neste processo.

\section{Conclusão}

É É diante de todas as questôes aqui expostas que pensamos o momento pelo qual passa o Rio de Janeiro nos dias de hoje. A cidade como projeto tenta se consolidar material e simbolicamente a partir, especialmente, da Operaçáo Urbana Porto Maravilha, e nos desdobramentos que esta intervenção incide na cidade. Mas o que está acontecendo atualmente é parte de um processo que começou nos anos de 1990 com o prefeito César Maia, que encantado com as transformaçôes urbanas de Barcelona, que se preparava para receber os Jogos Olímpicos de 1992, introduziu o modelo de planejamento estratégico, orientado por consultores cataláes que propunham a "fórmula" ideal para o Rio ser competitivo e ocupar um lugar no mercado das cidades globais.

Ocupar um lugar na seleta lista de cidades globais implica uma série de mudanças estruturais e comportamentais. $\mathrm{O}$ enfoque na arquitetura e no planejamento urbano é fundamental na formação discursiva que tem como principal objetivo o consenso público. A construção de imaginários urbanos e a participação da mídia neste processo são decisivas para que a competitividade seja naturalizada e aceita pela população como única saída rumo ao reconhecimento internacional. Um "novo" olhar sobre o urbano foi lançado pelo então prefeito César Maia, que para promover a imagem competitiva da cidade pôs em prática o primeiro plano estratégico do Rio de Janeiro - "Rio sempre Rio" - nos moldes dos planejamentos bem sucedidos e orientados para a globalização.

ComoBenjamim (2006)identifica nasExposiçôes Universaisocenárioideal para o homem moderno ocuparo seu lugar, eJaguaribe (2011) percebena Exposição Universal de 1922 o momento propício para o carioca sentir-se, efetivamente, 
parte do mundo moderno, os megaeventos do Rio de Janeiro neste século são fundamentais aos rituais de consumo da cidade, à consagração de cidade-marca, com papel determinante no mundo globalizado, e à formação de novas identidades, mesmo oferecendo como novidades açôes públicas que não são tão novas, mas que conseguem ser ressignificadas por um eficaz processo de marketing urbano. 


\section{Referências Bibliográficas}

ARANTES, Otília, VAINER, Carlos, MARICATO, Ermínia (orgs). A cidade do pensamento único: desmanchando consensos. Petrópolis, RJ: 2012.

BENJAMIN, Walter. Passagens. São Paulo: Imprensa Oficial, 2006.

BORJA, Jordi, CASTELLS, Manoel. As cidades como atores politicos. Novos estudos CEBRAP, n.45, julho de 1996.

Local y Global. Lá gestión de las ciudades em la era da información.Madri: United Nations for Human Sttlements/Taurus/ Pensamiento, 1997.

FREITAS, Ricardo. Rio de Janeiro, lugar de eventos: das exposiçóes universais do século XX aos megaeventos contemporâneos. Compos: 2011.

GUATTARI, Felix. "Restauração da Cidade Subjetiva". In: Caosmose: um novo paradigma estético. Editora 34, Rio de Janeiro, 1992.

JAGUARIBE, Beatriz. Imaginando a Cidade Maravilhosa: modernidade, espetáculo e espaços urbanos. Compos, 2011.

HARVEY, David. O direito à cidade. Revista Piauí, 2013.

http://revistapiaui.estadao.com.br/edicao-82/

tribuna-livre-da-luta-de-classes/o-direito-a-cidade

.A condição pós-moderna. São Paulo: Ediçôes Loyola, 1993. - A justiça social e a cidade. São Paulo: Hucitec, 1980.

ORLANDI, Eni. Cidade dos Sentidos. Campinas: Pontes, 2004. 